\title{
Alteration of airway responsiveness mediated by receptors in ovalbumin-induced asthmatic E3 rats
}

\author{
Jing-wen $\mathrm{LONG}^{1}$, Xu-dong YANG ${ }^{2}$, Lei CAO ${ }^{1}$, She-min $\mathrm{LU}^{2}$, Yong-xiao CAO ${ }^{1, *}$ \\ ${ }^{1}$ Department of Pharmacology, ${ }^{2}$ Department of Genetics and Molecular Biology, Xi'an Jiaotong University College of Medicine, Xi'an \\ 710061, China
}

\begin{abstract}
Aim: Airway hyperresponsiveness is a constant feature of asthma. The aim of the present study was to investigate airway hyperreactivity mediated by contractile and dilative receptors in an ovalbumin (OVA)-induced model of rat asthma.

Methods: Asthmatic E3 rats were prepared by intraperitoneal injection with OVA/aluminum hydroxide and then challenged with intranasal instillation of OVA-PBS two weeks later. The myograph method was used to measure the responses of constriction and dilatation in the trachea, main bronchi and lobar bronchi.

Results: In asthmatic E3 rats, $\beta_{2}$ adrenoceptor-mediated relaxation of airway smooth muscle pre-contracted with 5-HT was inhibited, and there were no obvious difference in relaxation compared with normal E3 rats. Contraction of lobar bronchi mediated by 5 -HT and sarafotoxin $6 \mathrm{c}$ was more potent than in the trachea or main bronchi. Airway contractions mediated by the endothelin $\left(\mathrm{ET}_{\mathrm{A}} \mathrm{A}_{\mathrm{receptor}} \mathrm{ET}_{\mathrm{B}}\right.$ receptor and $\mathrm{M}_{3}$ muscarinic receptor were augmented, and the augmented contraction was most obvious in lobar bronchi. The order of efficacy of contraction for lobar bronchi induced by agonists was ET-1, sarafotoxin 6c>ACh $>5-\mathrm{HT}$. OX8 (an antibody against CD8 ${ }^{+} \mathrm{T}$ cells) strongly shifted and OX35 (an antibody against CD4 ${ }^{+} \mathrm{T}$ cells) modestly shifted isoprenaline-induced concentration-relaxation curves in a nonparallel fashion to the left with an increased $R_{\max }$ in asthmatic rats and sarafotoxin $6 \mathrm{c}$-induced concentration-contractile curves to the right with a decreased $E_{\max }$.

Conclusion: The inhibition of airway relaxation and the augmentation of contraction mediated by receptors contribute to airway hyperresponsiveness and involve $\mathrm{CD} 8^{+}$and $\mathrm{CD} 4^{+} \mathrm{T}$ cells.
\end{abstract}

Keywords: airway hyperresponsiveness; asthma; contraction; rat; relaxation

Acta Pharmacologica Sinica (2009) 30: 965-972; doi: 10.1038/aps.2009.61

\section{Introduction}

Airway smooth muscle contraction plays important physiologic roles, matching ventilation with perfusion, conferring mechanical stability to airways lacking cartilage, and preventing toxic agents from reaching the alveolar air spaces. However, an exaggerated airway smooth muscle contractile response, a constant feature of asthma, is the main pathophysiological factor involved in the development of reversible airway obstruction. It also plays a central role in almost all of the pathophysiological and clinical aspects of asthma, such as bronchial hyperresponsiveness induced by direct and indirect contractile stimuli, chronic inflammation and airway structural changes ${ }^{[1]}$. Asthma is a chronic disease characterized by airway hyperresponsiveness, reversible air flow obstruction, bronchoconstriction $^{[2]}$, airway inflammation and remodeling ${ }^{[3,4]}$.

\footnotetext{
* To whom correspondence should be addressed.

E-mail yxy@xjtu.edu.cn

Received 2009-01-15 Accepted 2009-04-16
}

The term airway hyperresponsiveness has been used to describe the condition in which airways narrow too readily and too much in response to challenge with nonspecific contractile agonists ${ }^{[5]}$. Hyperresponsiveness is associated with receptor complement and downstream signaling events ${ }^{[6]}$. Bronchial hyperresponsiveness is the most important aspect of airway hyperresponsiveness. In vivo, bronchial hyperresponsiveness occurs because of a reduced threshold to a wide range of contractile stimuli acting either directly on bronchial smooth muscle via cell membrane receptors or indirectly through neural pathways and/or the release of bronchoconstrictive mediators from both inflammatory and structural cells. During the inflammatory process, the release of different mediators can cause both functional and structural alterations of the airways ${ }^{[7]}$ and the expression and function of some receptors in the airway smooth muscle are altered. Currently, the most widely used animal model for asthma research is the mouse. Many studies have found decreased $\beta$-adrenoceptor density in asthmatic airway tissues, including the lungs and 
lymphocytes ${ }^{[8,9]}$. We hypothesize that the up-regulation of contractile receptors and/or down-regulation of dilator receptors in the airway, especially in bronchial smooth muscle cells, underlie hyperresponsiveness. In this study, we investigated the reactivity of important contractile and dilative receptors in the bronchial smooth muscle in a rat model of ovalbumininduced asthma.

\section{Materials and methods Animals}

E3 rats (8-12 weeks, SPF) from the Section for Medical Inflammation, Lund University, Sweden, were housed in a special facility at the Department of Pharmacology, Xi'an Jiaotong University College of Medicine. The weights of the rats were $185 \pm 16 \mathrm{~g}$ and $250 \pm 21 \mathrm{~g}$ at the start and end, respectively, of the experiment. The rats were maintained on standard rodent diet with free access to food and water in a climate controlled environment and handled according to the guidelines provided by the Animal Center of Xi' an Jiaotong University College of Medicine.

\section{Chemicals}

Ovalbumin (OVA), aluminum hydroxide (Alum), endothelin-1 (ET-1), acetylcholine (ACh), 5-hydroxytryptamine (5-HT), isoprenaline hydrochloride and sarafotoxin $6 \mathrm{c}$ were purchased from Sigma, USA. Monoclonal antibodies against $\mathrm{CD} 4^{+} \mathrm{T}$ cells (OX35) and $\mathrm{CD}^{+} \mathrm{T}$ cells (OX8) were purified from supernatants of hybridomas using protein $\mathrm{G}$ affinity columns.

\section{Rat asthma model}

Each E3 rat in the model group was immunized intraperitoneally with $1 \mathrm{~mL}$ of emulsion containing $1 \mathrm{mg}$ OVA and $50 \mathrm{mg}$ Alum. Control rats received equal volumes of a phosphate buffered saline solution (PBS). Two weeks later, the rats were challenged intranasally with $100 \mu \mathrm{L}$ of OVA-PBS suspension containing $1 \mathrm{mg}$ OVA. Intranasal challenges were performed daily for 7 days ${ }^{[10]}$.

\section{In vitro pharmacology}

Rats were anesthetized and exsanguinated. The lungs were removed gently and immersed in cold oxygenated KrebsHenseleit solution (in mmol/L: $\mathrm{NaCl} 119, \mathrm{KCl} 4.7, \mathrm{CaCl}_{2}$ 2.6, $\mathrm{KH}_{2} \mathrm{PO}_{4} 1.2, \mathrm{MgSO}_{4} \cdot 7 \mathrm{H}_{2} \mathrm{O} 1.2, \mathrm{NaHCO}_{3} 25$, glucose 11.7, $\mathrm{pH}$ 7.4). The trachea, main bronchus and lobar bronchi were dissected free of adhering tissue and cut into $2 \mathrm{~mm}$ long segments under a light microscope. The trachea, main bronchus, or lobar bronchi segments were mounted on two L-shape metal prongs. One prong was connected to a force displacement transducer attached to a MacLab (ADInstruments) unit for continuous recording of isometric force. The other prong was connected to a displacement device, allowing adjustment of the distance between the two parallel prongs.

The mounted segments were immersed in temperature-controlled $\left(37^{\circ} \mathrm{C}\right)$ tissue baths containing $1 \mathrm{~mL}$ Krebs-Henseleit solution continuously equilibrated with a gas mixture of $95 \%$ $\mathrm{O}_{2}$ and $5 \% \mathrm{CO}_{2}$ to result in a stable $\mathrm{pH}$ of 7.4. The trachea, main bronchus and lobar bronchi segments were equilibrated for $1.5 \mathrm{~h}$ with resting tensions of $5 \mathrm{mN}, 2 \mathrm{mN}$, and $1 \mathrm{mN}$, respectively. Before the experiments began, each segment was contracted with a $\mathrm{K}^{+}$-rich $(45 \mathrm{mmol} / \mathrm{L})$ buffer solution in which $\mathrm{NaCl}$ was exchanged for an equimolar concentration of $\mathrm{KCl}$ to test contractile function. When two reproducible contractions had been achieved, the trachea, main bronchus and lobar bronchi were used for further experiments.

After equilibration, concentration-response curves were obtained by cumulative administration of ACh, 5-HT, sarafotoxin $6 \mathrm{c}$, and ET-1. The contractions are expressed as the percentage of pre-constriction with $45 \mathrm{mmol} / \mathrm{L} \mathrm{K}^{+}$-rich Krebs solution. The trachea, main bronchus and lobar bronchi were pre-contracted with 5-HT $(10 \mu \mathrm{mol} / \mathrm{L})$. After sustained tension was obtained, cumulative isoprenaline $(100 \mathrm{nmol} / \mathrm{L}-10$ $\mu \mathrm{mol} / \mathrm{L}$ ) was added to the bath and the isometric tension was recorded. The dilatation by isoprenaline was expressed as the percentage of pre-constriction with 5-HT.

\section{Calculations and statistics}

All data are expressed as means \pm SEM. The contractive response in each segment is expressed as the percentage of pre-constriction with $45 \mathrm{mmol} / \mathrm{L} \mathrm{K}^{+} . E_{\max }$ represents the maximum contraction induced by agonists. The relaxation by isoprenaline is expressed as the percentage of pre-constriction with 5-HT. $R_{\max }$ represents the maximum relaxation of isoprenaline. The $\mathrm{pEC}_{50}$ value was calculated from the line between the concentrations above and below the midpoint of the concentration-response curves. Two-way analysis of variance (ANOVA) with Dunnett's post-test was used for comparisons among all treatment groups. A $P$ value of less than 0.05 was regarded as significant.

\section{Results}

\section{Airway diameters of E3 rats}

The trachea, main bronchus and lobar bronchi were dissected free of adhering tissue under a light microscope and the diameters were measured with vernier calipers. The diameters of the trachea, main bronchus and lobar bronchi were 3.01 \pm 0.16 $\mathrm{mm}, 1.78 \pm 0.22 \mathrm{~mm}$, and $0.58 \pm 0.08 \mathrm{~mm}(n=20)$, respectively.

\section{Relaxation induced by isoprenaline}

Relaxation of the trachea, main bronchus and lobar bronchi was induced by isoprenaline in a concentration-dependent manner in both control rats and asthmatic rats. There was no obvious difference in the concentration-relaxation curves among the airway sections of the control rats (Figure 1A). In asthmatic rats, however, the concentration-relaxation curve of the lobar bronchi was shifted to the right compared with the trachea and main bronchi (Figure 1B). The $R_{\max }$ values of isoprenaline in the trachea, main bronchus and lobar bronchi in control rats were $94.5 \% \pm 1.9 \%, 90.3 \% \pm 2.2 \%$, and $93.1 \% \pm 3.1 \%$ $(n=7)$, respectively, with no significant differences $(P>0.05)$. Figure 2 showed the comparison of concentration-relaxation curves of the trachea, main bronchus, and lobar bronchi induced by isoprenaline in asthmatic and control rats. The $R_{\max }$ 

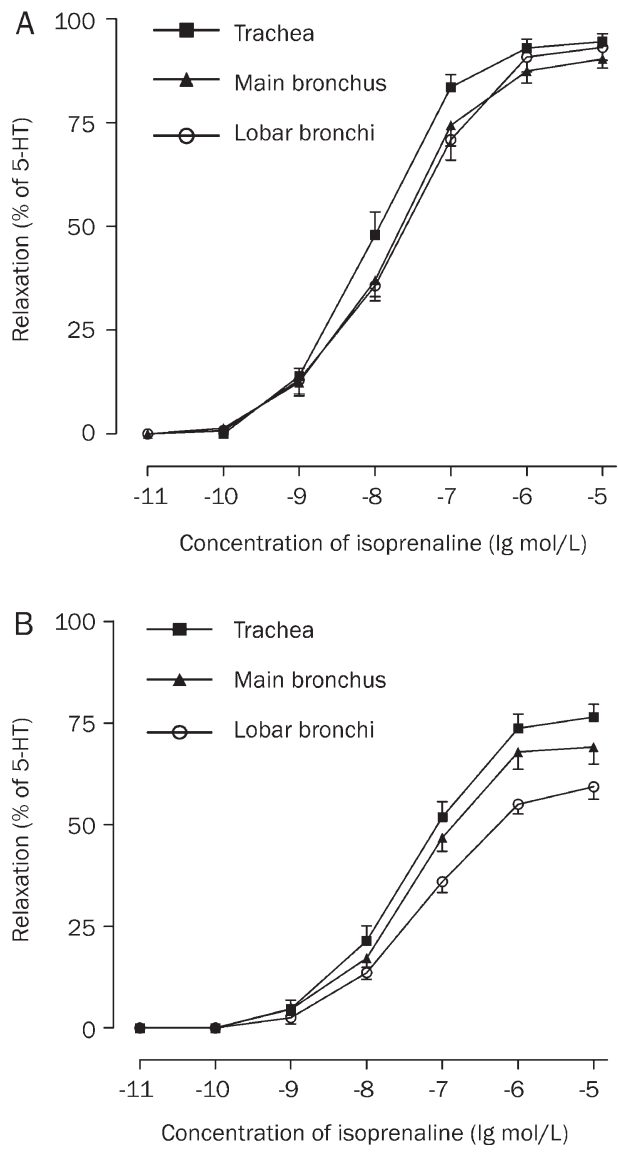

Figure 1. The concentration-relaxation curves induced by isoprenaline on the trachea, main bronchus, and lobar bronchi of control $(A)$ and ovalbumin-induced asthmatic E3 rats (B) pre-contracted with 5-HT. $n=7$. Data are shown as means \pm SEM.

values of isoprenaline in the trachea, main bronchus, and lobar bronchi of asthmatic rats were $76.5 \% \pm 3.1 \%, 69.1 \% \pm 3.2 \%$, and $59.3 \% \pm 3.1 \%(n=7)$, respectively; the $R_{\max }$ values for the lobar bronchi was lower than that of the trachea and main bronchus $\left(P<0.01\right.$ and $P<0.05$, respectively). The $R_{\max }$ values of the trachea, main bronchus, and lobar bronchi of asthmatic rats were also lower than that of control rats $(P<0.01)$. The $\mathrm{pEC}_{50}$ values of the concentration-relaxation curves of isoprenaline in the trachea, main bronchus, and lobar bronchi in asthmatic rats were $7.52 \pm 0.12,7.55 \pm 0.05$, and $7.35 \pm 0.10$, respectively, significantly lower than the $\mathrm{pEC}_{50}$ in the trachea, main bronchus, and lobar bronchi of control rats $[8.09 \pm 0.12(P<0.01), 7.87 \pm 0.13$ $(P<0.05)$, and $7.72 \pm 0.05(P<0.01)$, respectively].

\section{Contraction induced by $5-\mathrm{HT}$}

The $E_{\max }$ values induced by 5 -HT in the trachea, main bronchus, and lobar bronchi of E3 rats were $48.0 \% \pm 2.7 \%$, $39.1 \% \pm 3.7 \%$, and $91.4 \% \pm 4.2 \%(n=8)$, respectively. The contraction induced by 5-HT in the trachea and main bronchus of E3 rats was weaker than that in the lobar bronchi $(P<0.01$, Figure $3)$. There were no significant differences in the contractions of the trachea, main bronchus and lobar bronchi in asthmatic
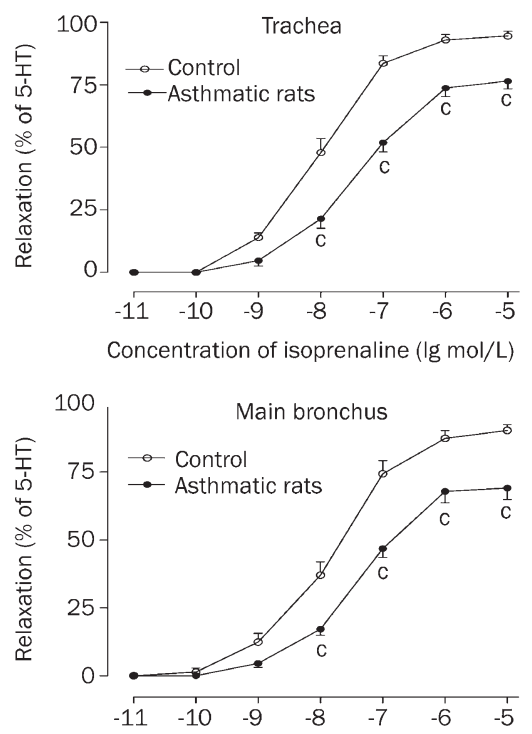

Concentration of isoprenaline (lg $\mathrm{mol} / \mathrm{L})$

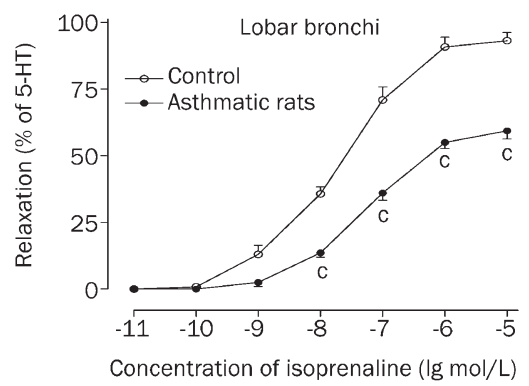

Figure 2. The concentration-relaxation curves induced by isoprenaline on the trachea, main bronchus, and lobar bronchi of asthmatic E3 rats pre-contracted with $5-\mathrm{HT}$. ${ }^{\mathrm{c}} P<0.01$ vs control. $n=7$. Data are shown as means \pm SEM.

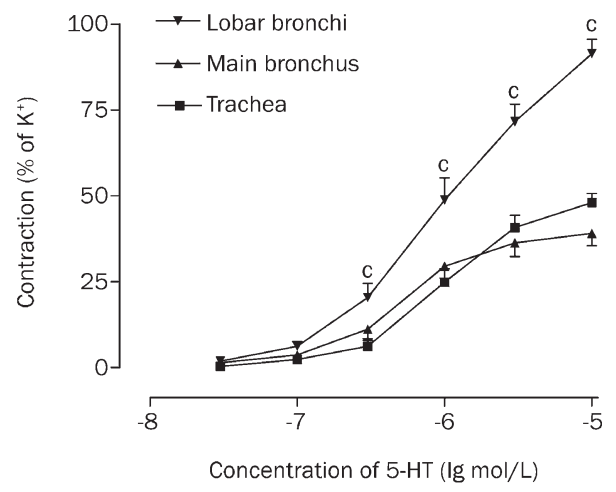

Figure 3. The concentration-contractile curves of the trachea, main bronchus, and lobar bronchi induced by $5-\mathrm{HT}$ in E3 rats. ${ }^{\mathrm{C}} \mathrm{P}<0.01$ vs the trachea and main bronchus. $n=8$. Data are shown as means \pm SEM.

rats compared with the same position of control rats (data not shown).

\section{Contraction induced by ACh}

$\mathrm{ACh}$ induced concentration-dependent contractions in the 
trachea, main bronchus, and lobar bronchi of control and asthmatic rats. In control rats, the $\mathrm{pEC}_{50}$ of the contraction curves induced by $\mathrm{ACh}$ in lobar bronchi was $4.40 \pm 0.09$, which was lower than that of the trachea $(5.76 \pm 0.08)$ and main bronchi (5.40 \pm 0.07$)$. However, the $E_{\max }$ values of $\mathrm{ACh}$ in the trachea, main bronchus, and lobar bronchi of control rats were the same (Figure 4). There was no obvious difference in the contraction curves of the trachea induced by ACh between control rats and asthmatic rats (data not shown).

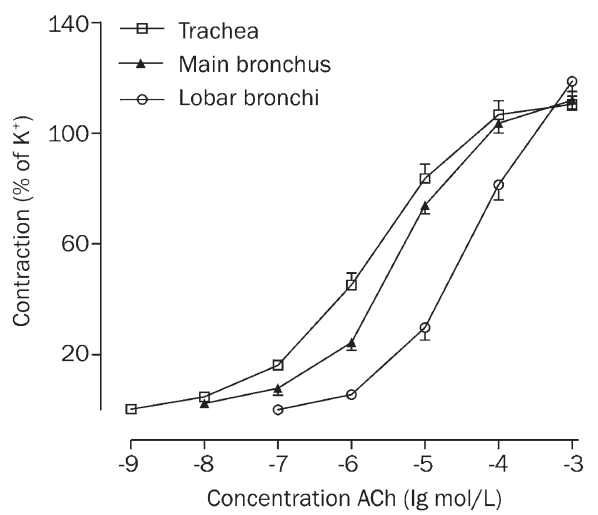

Figure 4. The concentration-contractile curves induced by ACh on the trachea, main bronchus, and lobar bronchi of E3 rats. $n=8$. Data are shown as means \pm SEM.

\section{Contraction mediated by endothelin receptors}

Sarafotoxin $6 \mathrm{c}$, a specific $\mathrm{ET}_{\mathrm{B}}$ receptor agonist, and endothelin-1, an activator of both $\mathrm{ET}_{\mathrm{A}}$ and $\mathrm{ET}_{\mathrm{B}}$ receptors, were used. When $\mathrm{ET}_{\mathrm{B}}$ receptor is desensitized by sarafotoxin $6 \mathrm{c}, \mathrm{ET}-1$ only excites the $\mathrm{ET}_{\mathrm{A}}$ receptor ${ }^{[11]}$. Cumulative sarafotoxin 6c (100 $\mathrm{nmol} / \mathrm{L}-3 \times 10 \mathrm{pmol} / \mathrm{L}$ ) was added to the baths and induced concentration-dependent contractions in the trachea, main bronchus, and lobar bronchi in both control rats and ovalbumin-induced asthmatic rats. The contraction of lobar bronchi induced by sarafotoxin $6 c$ was more potent than that of the trachea and main bronchus in both control and asthmatic rats (Figure 5). In asthmatic rats, the concentration-contraction curves induced by sarafotoxin $6 \mathrm{c}$ in the trachea, main bronchus and lobar bronchi were shifted to the left compared with that of control rats (Figure 6). The $E_{\max }$ values induced by S6c in the trachea, main bronchus, and lobar bronchi of E3 rats with asthma were $124.2 \% \pm 4.5 \%, 126.9 \% \pm 5.4 \%$ and $152.5 \% \pm 7.4 \%(n=8)$, respectively, which were higher than that of control rats $[92.3 \% \pm 4.1 \%, 93.2 \% \pm 4.7 \%$, and $106.9 \% \pm 4.8 \%$ $(P<0.01, n=8)$, respectively].

To study endothelin $\mathrm{ET}_{\mathrm{A}}$ receptor-mediated contractions, the experiment began with the desensitization of $\mathrm{ET}_{\mathrm{B}}$ receptors by inducing a concentration response curve to sarafotoxin $6 c^{[12]}$. In this case, the response to $100 \mathrm{pmol} / \mathrm{L}$ ET-1 was conducted. ET-1 induced a potent and sustained constriction of the trachea, main bronchus, and lobar bronchi of control and asthmatic rats. The contractions induced by ET- 1 in asthmatic
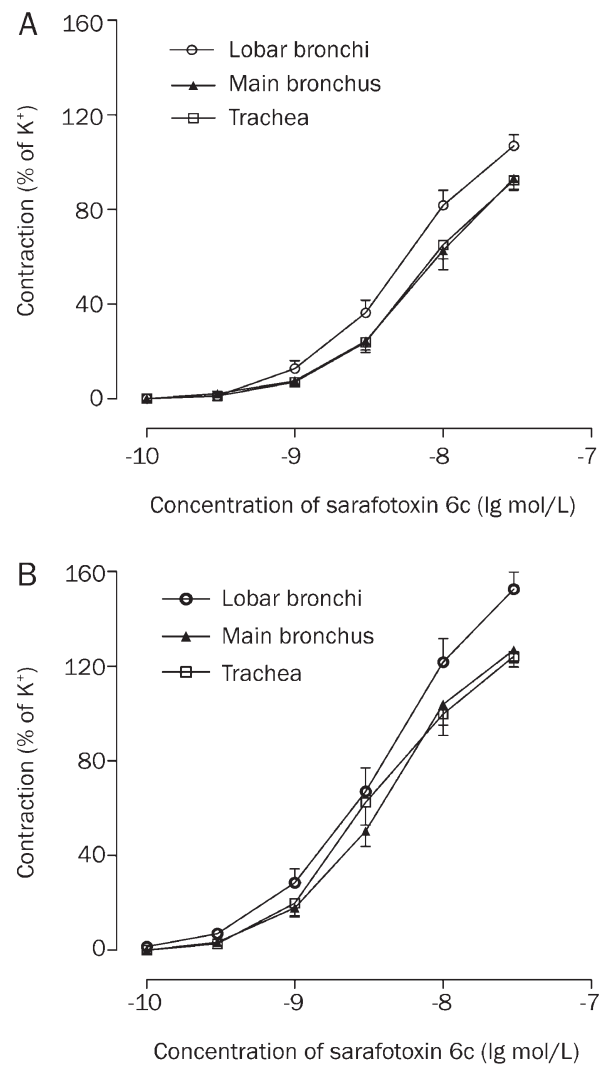

Figure 5. The concentration-contractile curves induced by sarafotoxin $6 c$ on the trachea, main-bronchus and lobar bronchi of control E3 rats (A) and asthmatic E3 rats induced by OVA (B). $n=8$. Data are shown as means \pm SEM.

rats were more powerful than those in control rats $(P<0.05$ or $P<0.01, n=6$, Figure 7).

\section{The effect of 0X35 and 0X8 antibodies on hyperresponsiveness}

E3 rats were randomly divided into control, asthmatic model, OX35-treated and OX8-treated groups. The asthmatic model was prepared by intraperitoneal injection of OVA/Alum (1 mg: $50 \mathrm{mg}$ ) in $1 \mathrm{~mL}$ per rat. Two weeks later, the rats were intranasally challenged with $100 \mu \mathrm{L}$ OVA-PBS suspension (1 $\mathrm{mg} / \mathrm{mL}, 50 \mu \mathrm{L}$ in each nostril with a micropipette) per day for 7 consecutive days. Before the intranasal solution was given on the first day, the rats of the OX35 group, the OX8 group, and the asthmatic model group were injected with $1 \mathrm{mg}$ of OX35, OX8 or normal saline, respectively. Twenty-four hours after the last challenge, the lobar bronchi were removed. The concentration-relaxation curves induced by cumulative isoprenaline on the lobar bronchi pre-contracted with $10 \mu \mathrm{mol} / \mathrm{L}$ 5-HT as well as the concentration-contractile curves induced by cumulative sarafotoxin $6 \mathrm{c}$ on the lobar bronchi were determined.

The results showed that isoprenaline induced a concentration-dependent relaxation of the lobar bronchi pre-contracted with 5-HT. The concentration-relaxation curve of asthmatic model rats was shifted in a nonparallel manner to the right, 

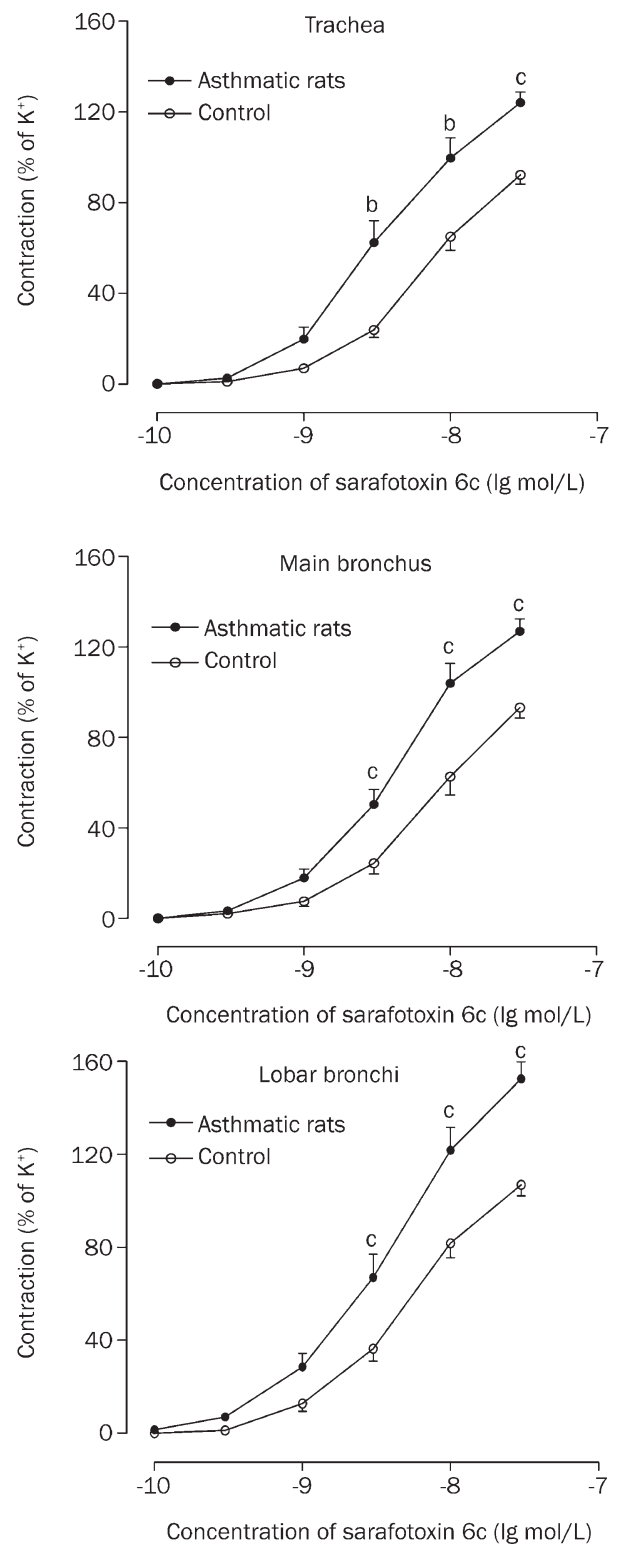

Figure 6. The concentration-contractile curves induced by sarafotoxin $6 \mathrm{c}$ on the trachea, main bronchus, and lobar bronchi of E3 rats with asthma induced by OVA. ${ }^{\mathrm{b}} P<0.05,{ }^{\mathrm{C}} P<0.01$ vs control. $n=8$. Data are shown as means \pm SEM.

with a decreased $R_{\max }$ of $56.4 \% \pm 2.3 \%$ compared with that of normal rats with a $R_{\max }$ of $82.5 \% \pm 1.8 \%(P<0.01, n=10)$. In rats treated with OX8 or OX35, the concentration-relaxation curves shifted in a nonparallel fashion to the left compared with that of asthmatic rats (strongly for OX8 treatment and modestly for OX35 treatment) and exhibited increased $R_{\max }$ values (Figure 8). The $R_{\max }$ values of the asthmatic model group, OX35 group, and OX8 group were $56.4 \% \pm 2.3 \%, 64.9 \% \pm 2.8 \%$, and $77.1 \% \pm 2.5 \%$, respectively. The $R_{\max }$ values of the OX35 group and the OX8 group were significantly higher than that of the control group $(P<0.01, n=10)$.

Figure 9 shows that sarafotoxin $6 \mathrm{c}$ induced contractions

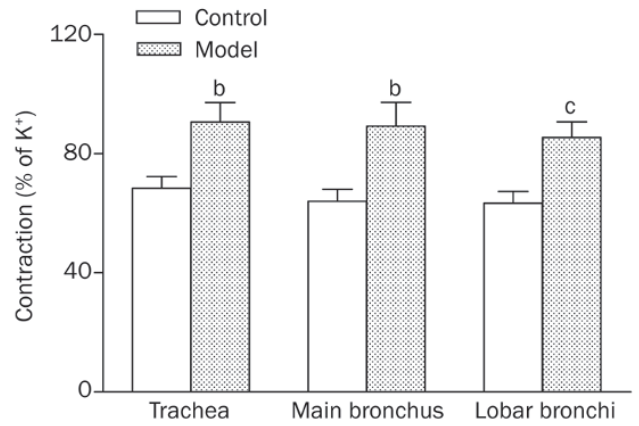

Figure 7. The contraction induced by $100 \mathrm{nmol} / \mathrm{L}$ ET-1 on the trachea, main bronchus and lobar bronchi of asthmatic E3 rats induced by OVA. ${ }^{\mathrm{b}} P<0.05$ vs control. $n=6$. Data are shown as means \pm SEM.

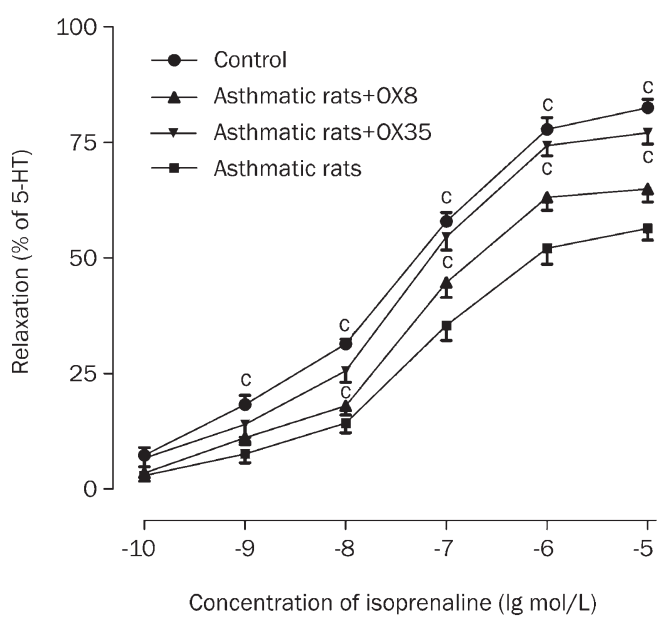

Figure 8. Effects of $0 \times 35$ (an antibody against $C D 4^{+} T$ cells) and $0 \times 8$ (an antibody against $\mathrm{CD} 8^{+} \mathrm{T}$ cells) on relaxation mediated by isoprenaline, a $\beta$ receptor agonist, of lobar bronchi of asthmatic E3 rats induced by OVA. ${ }^{\mathrm{b}} P<0.05,{ }^{\mathrm{c}} P<0.01$ vs asthmatic rats. $n=10$. Data are shown as means \pm SEM.

of the lobar bronchi in a concentration-dependent manner. The concentration-contractile curves of the asthmatic model group were shifted in a nonparallel fashion to the left with an increased $E_{\max }$ of $169.7 \% \pm 4.6 \%$ compared with the normal group, which had an $E_{\max }$ of $129.1 \% \pm 3.9 \%(P<0.01, n=10)$. OX8 treatment shifted the concentration-contractile curve of sarafotoxin $6 \mathrm{c}$ strongly to the right in a nonparallel fashion with a decreased $E_{\max }$ of $132.5 \% \pm 5.5 \%$ compared with the asthmatic model group, which had an $E_{\max }$ of $169.7 \% \pm 4.6 \%$ $(P<0.01, n=10)$. OX35 treatment elicited a modest shift in the concentration-contractile curve of sarafotoxin $6 \mathrm{c}$ to the right compared with the asthma model group, but there was no significant difference in $E_{\max }$ values between $156.1 \% \pm 6.1 \%$ and $169.7 \% \pm 4.6 \%(P>0.05, n=10)$. Thus, OX8 strongly and OX35 lightly antagonize the inhibition of relaxation mediated by $\beta_{2}$ adrenoceptors and the augmentation of contraction mediated by $\mathrm{ET}_{\mathrm{B}}$ receptors. 


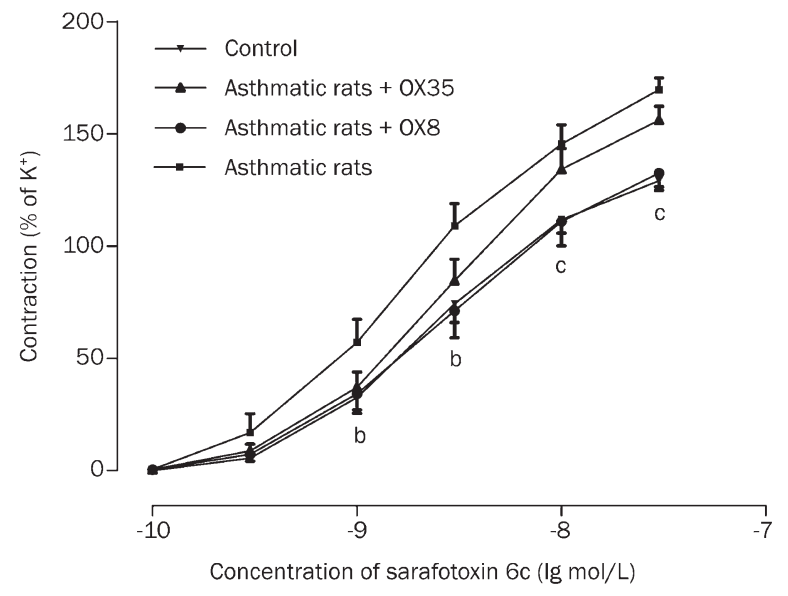

Figure 9. Effects of OX35 (an antibody against $\mathrm{CD} 4^{+} \mathrm{T}$ cells) and $\mathrm{OX} 8$ (an antibody against $\mathrm{CD} 8^{+} \mathrm{T}$ cells) on the contraction mediated by sarafotoxin $6 \mathrm{c}$, an endothelin $\mathrm{ET}_{\mathrm{B}}$ receptor agonist, of lobar bronchi of asthmatic $\mathrm{E} 3$ rats induced by OVA. $n=10$. ${ }^{b} P<0.05,{ }^{c} P<0.01$ vs Asthmatic rats. Data are shown as means \pm SEM.

\section{Discussion}

Allergic asthma is associated with allergen-specific airway hyperresponsiveness and inflammation. Rodent models of asthma, especially the OVA-induced model of airway inflammation, have become helpful in exploring the underlying mechanisms. However, these models only partly imitate the reaction in humans, with each model having pros and cons. In many respects, animal models are valuable for studying the underlying asthmatic pathomechanisms. However, the clinical course of asthma in many models depends on the genetic background ${ }^{[13]}$. Using rats, the genetically Th2-predisposed Brown Norway strain is most often used ${ }^{[14,15]}$ and the Fischer 344 strain is a relevant alternative ${ }^{[16]}$. We established an OVA/ Alum-based asthma model in E3 rats that is similar to human allergic asthma in several respects ${ }^{[17]}$ such as the Th-2 driven response to allergic sensitization, involvement of eosinophil infiltration of the airway, high levels of allergen specific IgE, increased number of $\mathrm{CD}^{+} \mathrm{T}$ cells in the phlegm of bronchi, incrassation of bronchial muscle, damage of bronchial epithelium, and infiltration by inflammatory cells. We also compared asthma models in different rat strains (DA, DAlu, E3, DE, and $\mathrm{SD})$. The results revealed increased ear swelling in E3, DE, and SD asthmatic rats. The ratio of eosinophils in bronchoalveolar lavage fluid and serum IgE was also increased. In asthmatic $\mathrm{SD}$ rats, the contractile function of bronchi mediated by $\mathrm{ET}_{\mathrm{B}}$ receptor agonist was increased. Significant changes in lung indices, the numbers of leukocytes in bronchoalveolar lavage fluids, and serum NO levels were not found in the five strains of asthmaticats. There were, however, alterations in the asthmatic characteristics of DA, DA.1U, E3, DE, and SD rats, and the change in asthmatic index was most obvious in E3 rats (Long et al, 2009 in press). In the present study, the E3 strain was used to evaluate receptor-mediated airway hyperresponsiveness.

Based on the Poiseuille law, airway resistance is linearly related to airway length but inversely proportional to the fourth power of the internal radius of the airway for laminar flow and inversely proportional to the fifth power of the internal radius of the airway for turbulent flow. Therefore, alteration of the airway radius is the most essential factor leading to airway resistance changes under physiological and pathological conditions. Our results showed that the diameter of lobar bronchi was $1 / 5.2$ of the trachea and $1 / 3.1$ of the main bronchus, suggesting that the lobar bronchi contribute much more to airway resistance than the main bronchus and the trachea. In normal rats, there were no significant differences in the potency and efficacy of dilations induced by isoprenaline, an agonist of $\beta_{2}$-adrenoceptors in the trachea, main bronchus, and lobar bronchi. 5-HT- and sarafotoxin 6c-induced potency and efficacy in the lobar bronchi were much greater and modestly greater, respectively, than that in the trachea and main bronchus. ACh-induced lobar bronchial potency was decreased but efficacy was comparable to that in the trachea and main bronchus. The order of efficacy $\left(E_{\max }\right)$ of contraction on lobar bronchi induced by agonists was sarafotoxin $6 \mathrm{c}>\mathrm{ACh}>5-\mathrm{HT}$. The concentration-contractile curve induced by ET-1 was not determined, so its efficacy is not known. The present results suggest that the efficacy of ET-1 should be greater than that of sarafotoxin $6 \mathrm{c}$ because the contraction induced by $100 \mathrm{nmol} / \mathrm{L}$ ET-1 reached $85 \% \pm 5.2 \%$. The efficacy of isoprenaline is high as well.

The present study showed that relaxation mediated by the $\beta_{2}$ adrenoceptor agonist isoprenaline was inhibited in the airway smooth muscle of asthmatic E3 rats. The inhibition in lobar bronchi was greater than that in the trachea and main bronchus. Compared with control rats, the concentration-relaxation curves for the trachea, the main bronchus, and especially the lobar bronchi were shifted to the right with decreased $R_{\max }$ and decreased $\mathrm{pEC}_{50}$. This means that airways relax insufficiently in response to treatment with $\beta_{2}$ adrenoceptor agonist or sympathetic activation. Also, the airways do not respond to levels of dilative agonist at which the control rat airways respond. These results suggest that the $\beta_{2}$-adrenoceptor in airways, especially the lobar bronchi, of asthmatic E3 rats is down-regulated, which supports our previous hypothesis for the mechanism underlying the asthmatic condition, ie, an intrinsic dysfunction of $\beta_{2}$-adrenoceptor results in impaired airway smooth muscle and bronchial smooth muscle constriction due to imbalanced sympathetic- and parasympatheticmediated airway tone ${ }^{[18]}$. Short-acting $\beta_{2}$-adrenoceptor agonists relieve acute episodes of bronchial smooth muscle spasm. However, chronic use of $\beta_{2}$-adrenoceptor agonists has been associated with worsening of bronchial hyperresponsiveness to spasmogens, loss of asthma control, and longer asthma exacerbations ${ }^{[19]}$ due to further down-regulation of the receptor. Furthermore, a single increase in $\beta_{2}$-adrenoceptor is not sufficient to produce the bronchoprotective effect, suggesting the mechanism is not the result of the action of a single factor.

$\mathrm{M}_{3}$ muscarinic receptor is the main muscarinic receptor mediating the contraction of airway smooth muscle. In the lungs, ACh released from the parasympathetic nerve stimu- 
lates $\mathrm{M}_{3}$ muscarinic receptor and induces the contraction of airways. The amount of ACh released from these nerves is limited locally by neuronal $\mathrm{M}_{2}$ muscarinic receptors. A dysfunction of $\mathrm{M}_{2}$ muscarinic receptors in asthma increases the release of $\mathrm{ACh}$ and evokes airway hyperreactivity ${ }^{[20]}$. However, the increase in potency and efficacy via ACh is not substantial, suggesting that the contribution of $\mathrm{M}_{3}$ receptor alteration to asthma is limited. Therefore, muscarinic antagonists are not ideal to treat asthma.

5-HT induces activation of $5-\mathrm{HT}_{2 \mathrm{~A}}$ receptors and results in bronchoconstriction $^{[21]}$. Inhaled 5-HT has no consistent effect on airway contraction in either normal or asthmatic subjects ${ }^{[22]}$. 5-HT-induced hyperresponsiveness in asthmatic E3 rats was not found in this study. However, levels of free 5-HT are elevated in the blood of asthmatic patients and these levels correlate with the severity of disease ${ }^{[23]}$. Therefore, a $5-\mathrm{HT}_{2 \mathrm{~A}}$ receptor antagonist, ketanserin, decreases OVA-induced airway hyperreactivity in mice ${ }^{[24]}$. Histamine is an important inflammation mediator, but we did not find any effect of histamine on rat airways. However, histamine increased the contraction of bronchi in asthmatic guinea pigs .

ET-1 is a potent bronchoconstrictor and plays an important role in the regulation of pulmonary functions. The response to ET-1 is mediated through $\mathrm{ET}_{\mathrm{A}}$ and $\mathrm{ET}_{\mathrm{B}}$ receptors. Both $\mathrm{ET}_{\mathrm{A}}$ and $\mathrm{ET}_{\mathrm{B}}$ receptors are present on smooth muscle cells of the airways and mediate strong contractions. $\mathrm{ET}_{\mathrm{B}}$ receptors are present on the airway epithelium as well, where they can induce relaxation through the release of nitric oxide ${ }^{[25]}$. Asthmatic inflammation causes disruption of the epithelium ${ }^{[26]}$, which decreases the dilation mediated by $\mathrm{ET}_{\mathrm{B}}$ receptors. The clearance of ET-1 in the airways through $\mathrm{ET}_{\mathrm{B}}$ receptors on epithelial cells is probably impaired, leading to enhanced access of ET-1 to underlying bronchial smooth muscle cells ${ }^{[27]}$. The production of relaxant factors such as nitric oxide is also compromised through ET-1 binding to receptors on epithelial cells. Therefore, $\mathrm{ET}_{\mathrm{A}}$ and $\mathrm{ET}_{\mathrm{B}}$ receptor-mediated contraction increases. Inhalation of ET-1 induces minor bronchoconstriction in non-asthmatic subjects ${ }^{[28]}$. Elevated levels of ET-1 are found in the bronchoalveolar lavage fluids and circulating blood from asthmatic patients ${ }^{[29]}$. Thus, the endothelin- 1 system is very important to airway hyperresponsiveness. $\mathrm{ET}_{\mathrm{A}}$ and $\mathrm{ET}_{\mathrm{B}}$ receptor antagonists inhibit airway hyperreactivity ${ }^{[30]}$, supporting our results.

In addition to $\mathrm{M}_{3}$ muscarinic receptor, histamine receptor, ET receptors, and the serotonin receptor, there are many contractile receptors relevant to asthma such as neurokinin $\left(\mathrm{NK}_{1}\right)$ $\mathrm{NK}_{2}$ ) receptors, cysteinyl leukotriene $\left(\mathrm{CysLT}_{1}\right)$ receptor, prostaglandin $\left(\mathrm{F}_{2 \alpha} / \mathrm{DP}_{2}\right)$ receptors, thromboxane receptors $(\mathrm{TP})$, bradykinin $\left(\mathrm{BK}_{1}\right)$ receptors, and adenosine $\left(\mathrm{A}_{1}\right)$ and thrombin (PAR1/2/3) receptors. Their contributions to airway hyperresponsiveness remain to be determined.

The contribution of $\mathrm{CD}^{+} \mathrm{T}$ cells and $\mathrm{CD}^{+} \mathrm{T}$ cells to the development of airway hyperresponsiveness and airway inflammation has recently received increased attention ${ }^{[31]}$. Our results show that OX8 (an antibody against $\mathrm{CD} 8^{+} \mathrm{T}$ cells) strongly and OX35 (an antibody against CD4 ${ }^{+} \mathrm{T}$ cells) modestly antagonize the inhibition of relaxation mediated by $\beta_{2}$ adrenoceptors as well as the augmentation of contraction mediated by $\mathrm{ET}_{\mathrm{B}}$ receptors, suggesting that $\mathrm{CD} 8^{+}$and $\mathrm{CD} 4^{+}$ $\mathrm{T}$ cells play important roles in airway hyperresponsiveness of asthmatic E3 rats and that $\mathrm{CD}^{+} \mathrm{T}$ cells are more potent than $\mathrm{CD}^{+} \mathrm{T}$ cells in asthma pathology. Our results support the suggestion that $\mathrm{CD}^{+} \mathrm{T}$ cells do contribute and might be necessary for airway hyperresponsiveness and eosinophilic airway inflammation ${ }^{[32]}$, and provide experimental evidence for the application of antibody against CD8 to treat asthma. $\mathrm{CD}^{+} \mathrm{T}$ cells, which are capable of secreting Th2 cytokines, have been described in asthmatic subjects and in animals sensitized and challenged with allergen. A subset of these IL-13producing $\mathrm{CD}^{+} \mathrm{T}$ cells, called effector memory $\mathrm{CD}^{+} \mathrm{T}$ cells in the mouse, express a high-affinity receptor for leukotriene B4 (BLT1). The expression of this receptor is essential for their accumulation in the lung and the development of airway hyperresponsiveness and airway inflammation ${ }^{[31]}$. A similar subset of $\mathrm{CD}^{+} / \mathrm{BLT}^{+} / \mathrm{IL}-13^{+} \mathrm{T}$ cells has also been identified in the bronchoalveolar lavage fluid of asthmatic subjects, suggesting a pathogenic role for this unique subset of CD8 ${ }^{+} \mathrm{T}$ cells in asthma. $\mathrm{CD}^{+} \mathrm{T}$ cells, particularly Th2 cells, play a pivotal role in allergic airway inflammation. Interactions between $\mathrm{CD}^{+}$and $\mathrm{CD} 8^{+} \mathrm{T}$ cells, in part through IL-4 during the sensitization phase, are essential to the development of $\mathrm{CD} 8^{+} \mathrm{IL}-13^{+} \mathrm{T}$ cell-dependent airway allergic inflammation ${ }^{[33]}$.

The present study demonstrates that in normal E3 rats, there is no significant difference in the potency and efficacy of relaxation induced by isoprenaline, an agonist of $\beta_{2}$-adrenoceptor in airways. 5-HT- and sarafotoxin 6c-induced potency and efficacy of contraction of lobar bronchi were much greater than on the trachea and slightly greater than on the main bronchus. ACh-induced lobar bronchial potency was less, but the efficacy was equal to that on the trachea and main bronchus. In asthmatic E3 rats, the relaxation of airway smooth muscle mediated by $\beta_{2}$ adrenoceptor was inhibited, and contractions mediated by $\mathrm{ET}_{\mathrm{A}}, \mathrm{ET}_{\mathrm{B}}$, and $\mathrm{M}_{3}$ muscarinic receptors were augmented. The alterations were the most obvious in lobar bronchi. The efficacy order of contraction for lobar bronchi induced by agonists was ET-1, sarafotoxin $6 \mathrm{c}>\mathrm{ACh}>5-\mathrm{HT}$. The inhibition of relaxation and the augmentation of contraction contribute to airway hyperreactivity, and both processes involve $\mathrm{CD}^{+}$and $\mathrm{CD}^{+} \mathrm{T}$ cells in asthmatic E3 rats.

\section{Acknowledgements}

The present work was supported by a grant from the National Natural Science Foundation of China (№ 30772566).

\section{Author contribution}

Yong-xiao CAO and She-min LU designed the research and revised the paper; Jing-wen LONG performed the research, analyzed the data and wrote the manuscript; Xu-dong YANG helped to perform the research. Lei CAO analyzed the data and revised the paper. 


\section{References}

1 Pelaia G, Renda T, Gallelli L, Vatrella A, Busceti MT, Agati S, et al. Molecular mechanisms underlying airway smooth muscle contraction and proliferation: implications for asthma. Respir Med 2008; 102: 1173-81.

2 Malik R, Priyadarsiny P, Shirumalla R, Soni R, Ray A, Saini K. Gene expression profile of ovalbumin-induced lung inflammation in a murine model of asthma. J Investig Allergol Clin Immunol 2008; 18: 106-12.

3 Zhu MM, Zhou QH, Zhu MH, Rong HB, Xu YM, Qian YN, et al. Effects of nebulized ketamine on allergen-induced airway hyperresponsiveness and inflammation in actively sensitized Brown-Norway rats. J Inflamm (Lond) 2007; 4: 10.

4 Bian T, Yin KS, Jin SX, Zhang XL, Zhou JY, Ma XQ, et al. Treatment of allergic airway inflammation and hyperresponsiveness by imiquimod modulating transcription factors T-bet and GATA-3. Chin Med J (Engl) 2006; 119: 640-8.

5 Woolcock AJ, Peat JK. Epidemiology of bronchial hyperresponsiveness. Clin Rev Allergy 1989; 7: 245-56.

6 Fredberg JJ. Bronchospasm and its biophysical basis in airway smooth muscle. Respir Res 2004; 5: 2.

7 Bousquet J, Jeffery PK, Busse WW, Johnson M, Vignola AM. Asthma. From bronchoconstriction to airways inflammation and remodeling. Am J Respir Crit Care Med 2000; 161: 1720-45.

8 Barnes PJ, Dollery CT, MacDermot J. Increased pulmonary alphaadrenergic and reduced beta-adrenergic receptors in experimental asthma. Nature 1980; 285: 569-71.

9 Emala C, Black C, Curry C, Levine MA, Hirshman CA. Impaired betaadrenergic receptor activation of adenylyl cyclase in airway smooth muscle in the basenji-greyhound dog model of airway hyperresponsiveness. Am J Respir Cell Mol Biol 1993; 8: 668-75.

10 Murai A, Abe M, Hayashi Y, Sakata N, Katsuragi T, Tanaka K. Comparison study between the mechanisms of allergic asthma amelioration by a cysteinyl-leukotriene type 1 receptor antagonist montelukast and methylprednisolone. J Pharmacol Exp Ther 2005; 312: 432-40.

11 Li J, Cao YX, Liu H, Xu CB. Enhanced G-protein coupled receptorsmediated contraction and reduced endothelium-dependent relaxation in hypertension. Eur J Pharmacol 2007; 557: 186-94.

12 Li J, Cao YX, Cao L, Liu Y, Xu CB. Heat stress alters G-protein coupled receptor-mediated function and endothelium-dependent relaxation in rat mesenteric artery. Eur J Pharmacol 2008; 588: 280-5.

13 Hylkema MN, Hoekstra MO, Luinge M, Timens W. The strength of the OVA-induced airway inflammation in rats is strain dependent. Clin Exp Immunol 2002; 129: 390-6.

14 Bochner BS, Hamid Q. Advances in mechanisms of allergy. J Allergy Clin Immunol 2003; 111 (3 Suppl): S819-23.

15 Schuster M, Tschernig T, Krug N, Pabst R. Lymphocytes migrate from the blood into the bronchoalveolar lavage and lung parenchyma in the asthma model of the brown Norway rat. Am J Respir Crit Care Med 2000; 161: 558-66.

16 Skripuletz T, Schmiedl A, Schade J, Bedoui S, Glaab T, Pabst R, et al. Dose-dependent recruitment of $\mathrm{CD}_{2} 5^{+}$and $\mathrm{CD} 26^{+} \mathrm{T}$ cells in a novel F344 rat model of asthma. Am J Physiol Lung Cell Mol Physiol 2007; 292: L1564-71.

17 Long JW, Cao YX, Lu SM. Airway hypersensitivity in ovalbumin-induced asthma model of rats and guinea pigs in vivo. Xi'an: Xi'an Jiaotong
University; 2006.

18 Lipworth BJ. Long-acting beta(2)-adrenoceptor agonists: a smart choice for asthma? Trends Pharmacol Sci 2007; 28: 257-62.

19 Lin R, Peng H, Nguyen LP, Dudekula NB, Shardonofsky F, Knoll BJ, et al. Changes in beta 2-adrenoceptor and other signaling proteins produced by chronic administration of 'beta-blockers' in a murine asthma model. Pulm Pharmacol Ther 2008; 21: 115-24.

20 Fryer AD, Adamko DJ, Yost BL, Jacoby DB. Effects of inflammatory cells on neuronal M2 muscarinic receptor function in the lung. Life Sci 1999; 64: 449-55.

21 Zhang $\mathrm{Y}$, Cardell LO, Adner M. IL-1beta induces murine airway $5-\mathrm{HT}_{2 \mathrm{~A}}$ receptor hyperresponsiveness via a non-transcriptional MAPK-dependent mechanism. Respir Res 2007; 8: 29.

22 Cushley MJ, Wee LH, Holgate ST. The effect of inhaled 5-hydroxytryptamine (5-HT, serotonin) on airway calibre in man. $\mathrm{Br} J$ Clin Pharmacol 1986; 22: 487-90.

23 Lechin F, van der Dijs B, Orozco B, Lechin M, Lechin AE. Increased levels of free serotonin in plasma of symptomatic asthmatic patients. Ann Allergy Asthma Immunol 1996; 77: 245-53.

24 De Bie JJ, Henricks PA, Cruikshank WW, Hofman G, Jonker EH, Nijkamp FP, et al. Modulation of airway hyperresponsiveness and eosinophilia by selective histamine and $5-\mathrm{HT}$ receptor antagonists in a mouse model of allergic asthma. Br J Pharmacol 1998; 124: 857-64.

25 Naline E, Bertrand C, Biyah K, Fujitani Y, Okada T, Bisson A, et al. Modulation of ET-1-induced contraction of human bronchi by airway epithelium-dependent nitric oxide release via $\mathrm{ET}(\mathrm{A})$ receptor activation. Br J Pharmacol 1999; 126: 529-35.

26 Laitinen LA, Laitinen A, Haahtela T. Airway mucosal inflammation even in patients with newly diagnosed asthma. Am Rev Respir Dis 1993; 147: 697-704.

27 Fukuroda T, Fujikawa T, Ozaki S, Ishikawa K, Yano M, Nishikibe M. Clearance of circulating endothelin-1 by $\mathrm{ET}_{\mathrm{B}}$ receptors in rats. Biochem Biophys Res Commun 1994; 199: 1461-5.

28 Chalmers GW, Little SA, Patel KR, Thomson NC. Endothelin-1-induced bronchoconstriction in asthma. Am J Respir Crit Care Med 1997; 156: 382-8.

29 Gawlik R, Ziora D, Rogala E, Pluskiewicz W. Levels of endothelin-I in bronchoalveolar fluid of patients with selected respiratory tract diseases. Pneumonol Alergol Pol 1997; 65: 333-7.

30 Henry PJ, Mann TS, D’Aprile AC, Self GJ, Goldie RG. An endothelin receptor antagonist, SB-217242, inhibits airway hyperresponsiveness in allergic mice. Am J Physiol Lung Cell Mol Physiol 2002; 283: L1072-8.

31 Gelfand EW, Dakhama A. CD8 ${ }^{+}$T lymphocytes and leukotriene B4: novel interactions in the persistence and progression of asthma. J Allergy Clin Immunol 2006; 117: 577-82.

32 Hamelmann E, Oshiba A, Paluh J, Bradley K, Loader J, Potter TA, et al. Requirement for $\mathrm{CD}^{+} \mathrm{T}$ cells in the development of airway hyperresponsiveness in a marine model of airway sensitization. J Exp Med 1996; 183: 1719-29.

33 Koya T, Miyahara N, Takeda K, Matsubara S, Matsuda H, Swasey C, et al. $\mathrm{CD}^{+} \mathrm{T}$ cell-mediated airway hyperresponsiveness and inflammation is dependent on $\mathrm{CD}^{+}{ }^{+} \mathrm{IL}-4^{+} \mathrm{T}$ cells. J Immunol 2007; 179: 2787-96. 